\title{
Sharper Fund Management
}

\author{
Patrick Burns*
}

17th November 2003

\begin{abstract}
The current practice of fund management can be altered to improve the lot of both the investor and the fund manager. Tracking error constraints in mandates can be replaced by an evaluation of the added value provided to the investor by the fund manager. The value of the manager depends not only on the outperformance of the manager's fund, but also on its volatility and its correlation to the rest of the investor's portfolio. Hyperpassive funds - an approach suggested by the new mandate scheme-show promise.
\end{abstract}

\section{Introduction}

When given two choices with the same expected return, only a crazy person would select the one with more risk. Fund management, at present, is crazy.

This paper provides a brief tour of what is wrong with tracking error constraints, how mandates might alternatively be written, and how the fund managers would be evaluated under these new mandates. Some possible additional steps are also discussed. The mathematical details of ideas advocated here can be found in [Burns, 2003].

\section{The Tyranny of Tracking Errors}

Typically a fund manager is constrained to have no more than a given tracking error from some index and the manager is expected to outperform the index. While seemingly rational, this has two major problems. The investor has no idea if managers are really adding value or not. Fund managers are often limited from using their skill to best advantage.

Suppose that a manager has outperformed the benchmark, and stayed within the tracking error constraint. This is thought to be a good thing. However, in actuality it may or may not be good for the investor. If the volatility of the manager's fund is too high or its correlation with the rest of the investor's

${ }^{*}$ This report can be found in the working papers section of the Burns Statistics website http://www.burns-stat.com/. 
portfolio is too high, then the manager will be hurting the investor. Conversely a manager that underperforms the benchmark might actually be improving the investor portfolio. To take a ludicrously extreme example, a fund that outperforms by $3 \%$, has twice the volatility of the index and a correlation of $80 \%$ with the rest of the investor's portfolio is very probably bad for the investor to buy. A fund that underperforms by $3 \%$, has half the volatility of the index and a correlation of $-80 \%$ with the rest of the investor's portfolio is surely good for the investor to buy.

More realistically, a fund manager may outperform the benchmark merely by leveraging - either actually or effectively - the benchmark. Is this good for the investor? Probably not, but even if it is, the investor can surely leverage more cheaply than through an active manager.

Tracking error constraints fail to encourage fund managers to add value to the investor as best they can. The effect of the fund on the risk of the investor's portfolio is not taken into account.

The tracking error methodology is bad for the fund managers as well as the investors. Because tracking error constraints are generally quite tight, the fund manager must hold the most influential assets in the index just to keep the tracking error at bay. The fund manager may believe that the largest asset is absolutely the most doomed in the world, but still must buy it. Large companies are bought solely because they are large.

\section{$3 \quad$ Setting Mandates}

A mandate should guide the fund manager towards improving the state of the investor's entire portfolio. We've seen that the tracking error methodology, which depends on the outperformance of the fund and its tracking error to the benchmark, fails to do this.

The added value of the fund manager is determined by:

- The outperformance of the fund.

- The volatility of the fund.

- The volatility of the benchmark.

- The volatility of the investor's portfolio that is not in the manager's fund.

- The correlation of the fund with the rest of the investor's portfolio.

- The correlation of the benchmark with the rest of the portfolio.

- The fraction of the investor's portfolio managed by the fund.

- The risk aversion of the investor.

In order to set up a mandate using these numbers, the investor only needs to specify: 
- The benchmark for the fund.

- The fraction of the investor's portfolio to be managed by the fund.

- A proxy for the remainder of the investor's portfolio.

- The risk aversion.

The first two of these are trivial, the latter two are not hard to get. An approximation for the rest of the investor's portfolio can be a weighted average of the benchmarks for the other parts of the portfolio. For example the proxy for the remainder of the portfolio relative to an equity growth fund might be a weighted average of a bond index, an equity index and an equity value index. Investors can estimate their own risk aversion by performing a few thought experiments or by doing some simulations.

There are three properties of the fund that matter: its outperformance, its volatility and its correlation with the rest of the investor's portfolio. While the evaluation of the fund should use realized values, an approximation of when the fund manager is adding value can be created at the time that the mandate is set. Such an approximation might look like Figure 1. This shows the level of outperformance at which the investor is neither gaining nor losing utility as the volatility and correlation of the fund varies. For example if the volatility of the fund is $15 \%$ and the correlation of the fund with the rest of the investor's portfolio is $5 \%$, then the fund can underperform the benchmark by as much as 100 basis points and still not be detracting from the investor.

This method of setting a mandate unchains the fund manager from following the benchmark so closely. In particular, there is more temporal flexibility. Fund managers that do not believe that opportunity is constant can adjust the volatility and correlation of their funds. When they do not see good opportunities, they can move toward the lower left of Figure 1. As opportunities arise, they can feel justified in increasing the fund volatility and/or its correlation with the rest of the investor's portfolio.

This discussion has presumed that the fund is bespoke to a single investor. Funds that have a number of investors may use this type of mandate as well. The fraction of the investor's portfolio, the risk aversion and the remainder of the portfolio need to be estimated for the typical investor.

\section{Testing Managers}

The proposed mandate evaluates fund managers by an adjustment to their outperformance of the benchmark based on the fund's volatility and its correlation with the rest of the investor's portfolio. This is easily computed, and we call it the effective outperformance of the fund.

Table 1 shows the results from a hypothetical case where three funds are compared. By standard analysis Fund B is the best, followed by Fund C, while Fund A looks bad. When volatilities and correlations are accounted for, Fund B 
Figure 1: Approximate break-even outperformance (in basis points) for a particular mandate.

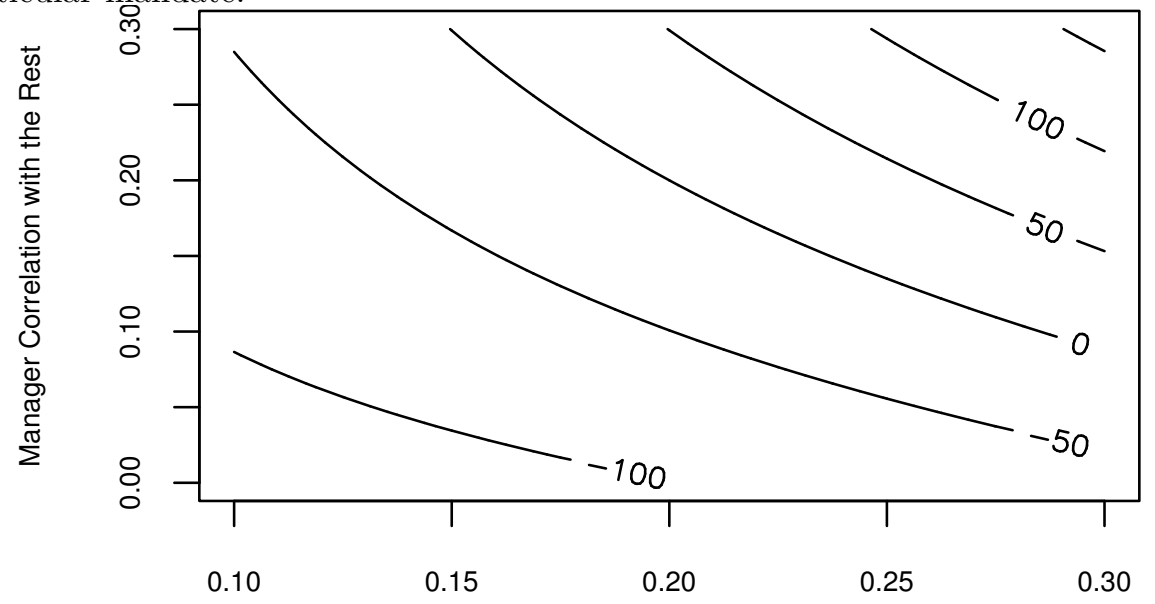

Manager Volatility

Table 1: Example evaluations of effective alpha.

\begin{tabular}{|c|c|c|c|c|}
\hline & Volatility & Correlation with rest & Raw alpha & Effective alpha \\
\hline \hline Fund A & $17 \%$ & $15 \%$ & $-100 \mathrm{bps}$ & $-12 \mathrm{bps}$ \\
\hline Fund B & $26 \%$ & $24 \%$ & $200 \mathrm{bps}$ & $168 \mathrm{bps}$ \\
\hline Fund C & $30 \%$ & $40 \%$ & $100 \mathrm{bps}$ & $-93 \mathrm{bps}$ \\
\hline
\end{tabular}

is still the best but the roles of $\mathrm{A}$ and $\mathrm{C}$ are reversed. These evaluations are for the same hypothetical mandate as Figure 1. However, the adjustments are not exactly what the plot would suggest because the realized volatility of the rest of the investor portfolio and its correlation with the benchmark do not equal the forecast values.

While tracking error does not enter into the calculation of the effective alpha of a fund, it does still have a supporting role. In general the larger the tracking error, the more variable is the effective alpha. That is, larger tracking errors imply that it will take extra time to determine the quality of the fund manager to a given precision.

\section{$5 \quad$ Hyperpassive Funds}

A "hyperpassive" fund will reduce volatility to a minimum and possibly reduce its correlation to the rest of the investor's portfolio while trying to maintain the same expected return. Since there is no search for outperformance, such funds 
Table 2: Results of a hyperpassive optimization.

\begin{tabular}{|c|c|c|c|}
\hline & Dow & DAX 100 & FTSE 100 \\
\hline \hline Index volatility & $18.8 \%$ & $22.9 \%$ & $16.3 \%$ \\
\hline Fund volatility & $16.8 \%$ & $14.0 \%$ & $13.4 \%$ \\
\hline Annualized index return & $8.4 \%$ & $-0.6 \%$ & $1.2 \%$ \\
\hline Annualized fund return & $7.5 \%$ & $2.4 \%$ & $5.7 \%$ \\
\hline Tracking error & $10.1 \%$ & $15.6 \%$ & $9.0 \%$ \\
\hline
\end{tabular}

can be operated cheaply - perhaps even cheaper than a traditional index fund. Advantages of hyperpassive funds over index funds include not being forced to hold all of the assets in the index, and not being forced to trade when the index changes.

This section presents the results of a preliminary look to see how hyperpassive funds might perform. Ten years of weekly data for the Dow Industrials, the DAX 100 and the FTSE 100 were used. In each of the three cases an artificial market-capitalized index was created so that survival bias would not be an issue. Portfolio optimizations were performed at 20 week intervals. The correlations and volatilities used in the optimizations were based on the previous 50 weeks of data.

In the experiment presented, no more than half of the assets were allowed in the fund and the turnover (buys plus sells) was limited to $20 \%$ per annum. The weights of individual stocks were constrained to be between 0 and $10 \%$. Table 2 provides the resulting statistics.

The results for the Dow in Table 2 are not especially encouraging - the volatility is only marginally lower for the fund and the return is lower. Given that the Dow is a small group of rather homogenous stocks, this is not surprising. The picture for the other two indices is quite different. In both of the other cases the return for the fund is higher than that for the index while the volatility is lower. The volatility of the fund is substantially smaller than the index volatility in the case of the DAX. Since there is no particular investor that we have in mind, there is no way to evaluate the correlation of the funds or their effective alphas.

Having a higher return with a lower volatility seems like it is too good to be true. To some extent it is - the outperformance of the hyperpassive funds is concentrated in the bear market at the end of the data period. Figure 2 shows the relative performance for the FTSE fund. It has a clear tendency to underperform through 1999, then it dramatically outperforms in the final years. Thus time frames that do not include an extended bear market are likely to show underperformance - constraints might be appropriate to try to avoid the underperformance.

The analysis presented has taken no account of dividends. It seems more than likely that the addition of dividends would improve the performance of hyperpassive funds since less volatile stocks often have higher dividends. 
Figure 2: Performance of the hyperpassive FTSE fund relative to the index.

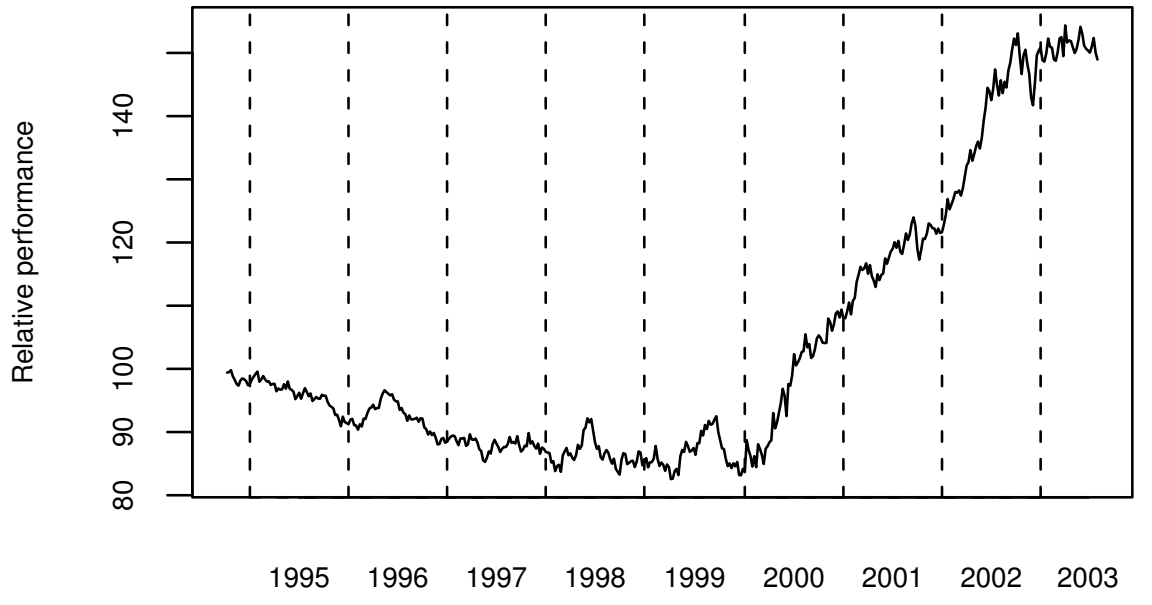

\section{Skewness}

To this point we have ignored the possibility of skewed returns. All else being equal, positive skewness (where large positive returns are more common than negative returns of the same magnitude) is to be preferred. If there is skewness in a portfolio, we need to change the utility.

In the simple case without skewness, specifying the utility is merely selecting a risk aversion parameter. With skewness the specification becomes somewhat harder. However, the exercise could be very valuable (even if only to demand serious thought about preferences).

Buying options to create positive skewness can be useful. This is, in effect, buying insurance against big losses. The cost of the insurance needs to be weighed against the reduced chance of large losses.

Options are undoubtedly underutilized - partly because utilities are not generally specified that allow for skewness, and partly because of the belief that options are dangerous. Selling insurance can be dangerous, but buying insurance is not. Buying too much insurance is wasteful. Purchasing the right amount of insurance is the essence of prudence.

\section{Summary}

Mandates that demand tracking error constraints force the fund managers not to be truly active, while at the same time not pointing the managers towards the best way of helping the investor. The outperformance of a fund can be adjusted 
to account for the volatility of the fund and its correlation with the remainder of the investor's portfolio. The existence of the adjusted outperformance allows mandates that focus on the value added to the investor by the fund manager.

It is natural to consider skewness as well as return and volatility. This is a reasonably straightforward next step in the revised paradigm, but is quite foreign in the tracking error world.

Hyperpassive funds - where the volatility is minimized - become a possibility in the new regime. Some experiments presented here seem to validate the idea. It appears plausible even to outperform some equity indices while maintaining lower volatility.

The proposed mandates allow active managers to be more active. Even more importantly, they focus the managers - active or not-on being useful to the investor.

\section{References}

[Burns, 2003] Burns, P. (2003). Portfolio sharpening. Working paper, Burns Statistics, http://www.burns-stat.com/. 